\title{
PALESTRA: \\ Sobre conceitos de cultura e a \\ educação musical no brasil atual
}

Acácio Tadeu de C. Piedade

\section{"Cultura"}

$\mathrm{Na}$ atualidade muito se tem falado de cultura, multiculturalismo, etnografia e relativismo. 0 crescente uso destes conceitos em diversos campos das ciências humanas e humanidades em geral, bem como em outras áreas, representa, para os antropólogos, ao mesmo tempo motivo de satisfação e de inquietude. De satisfação porque, afinal, foi na antropologia que estes conceitos foram duramente forjados e amplamente debatidos, e é nesta disciplina que se consolidou a reflexão sobre a diversidade das culturas humanas; e de inquietude porque os conceitos são usados, na maioria das vezes, de forma um tanto descomprometida, despregada de seu paradigma teórico originário. 0 fato de que "tais conceitos mantêm compromissos com perspectivas teóricas diferenciadas que indicam os limites, alcance e desdobramentos de uma análise" (Valente e Gusmão, 1999) é muitas vezes negligenciado, ou mesmo ignorado. O conceito 
mais em voga, o de "cultura", representa um conjunto de problemas teóricos e ideológicos que têm sido construídos, discutidos, abandonados, retomados e recriados desde o início do século no campo da antropologia, sendo que uma conclusão geral e genérica a que se pode chegar é que "cultura" não é um conceito, mas sim vários, cada sendo um profundamente calcado em uma visão de mundo ou paradigma teórico, e carregando em si toda a ideologia subjacente a este pensamento.

$\mathrm{Na}$ vasta literatura sobre a chamada pósmodernidade pode-se encontrar sinais que indicam três atitudes básicas: uma nova forma social, uma nova sensibilidade cultural e uma crítica à modernidade, embebida de um pessimismo cultural de "tipo nietzscheano". Um dos autores importantes da literatura em questão é Bauman (1992), que contribui para uma teoria sociológica da pós-modernidade com um modelo onde haveria uma relação ao mesmo tempo de continuidade e discontinuidade entre a condição social atual pós-modernidade - e a formação precedente modernidade. Para uma tal teoria, Bauman crê ser necessário construir um espaço cognitivo organizado por diferentes pressupostos e necessidades, assumindo o desequilíbrio na condição social e focalizando no agente e no habitat onde ele opera. Este espaço é preenchido, em parte, pelo velho relativismo cultural, que aparece renovado no quadro do pós-moderno. Mais do que nunca, é hoje crucial para "diferentes povos formar imagens concretas 
complexas um do outro, assim como das relações de conhecimento e de poder que os conectam; mas nenhum método científico ou instâncias éticas soberanas podem garantir a imagem de tais imagens" (Clifford, 1988). Considerar a autonomia do agente e o pluralismo da autoridade nos relacionamentos é uma contribuição evidente para o campo de uma ética pós-moderna (Rundell, 1992).

Isto posto, creio a antropologia da segunda metade do século $X X$ age basicamente em dois fronts: a salvaguarda das formas culturais de vida distintas em relação a um processo de ocidentalização e uma forma de autocrítica cultural. 0 desenvolvimento da antropologia fortalece seu sentido crítico, e emergem a partir dos anos 60 algo como uma "nova sensibilidade para a dificuldade de representar as diferenças culturais" e um "reconhecimento sofisticado das realidades históricas e políticas", que não se fazia presente em escritos anteriores (Marcus e Fischer, 1986).

Instaura-se uma crise nas ciências humanas que surge a partir de diversos fatores como o empréstimo fluido de idéias e métodos de uma disciplina a outra, o solapamento do positivismo, a crítica ao ideal de crescimento econômico e progresso, as implicações da contextualidade e da indeterminação na construção de modelos filosóficos, a possibilidade de uma inteligência artificial, a teoria do caos e o fim da autoridade das "grandes teorias" e metanarrativas (Lyotard, 1986) ; é 
uma crise na idéia de representação ela mesma, que denuncia a necessidade de se criar outras estratégias para produzir descrições realistas da sociedade, e que levem em conta o processo de mudança em si próprio.

Podemos dizer que os conceitos como o de "cultura" estão profundamente vinculados a teorias gerais, que se formam e que são aceitas numa determinada época, sendo ali compartilhadas por uma comunuidade científica. Como afirma Thomas Kuhn (1975), estes paradigmas são limitados, e é justamente a partir das reentrâncias obscuras que seu escopo não atinge (ou omite-se em trabalhar) que vai ser elaborado um novo corpo de teorias que detonará a queda do modelo vigente e a ascensão de um novo paradigma (uma revolução científica, nas palavras de Kuhn).

O caso da antropologia, na visão de Roberto Cardoso de Oliveira, é diferente: há quatro paradigmas teóricos básicos constituindo uma matriz disciplinar, sendo que cada um vale à sua maneira, todos sobrevivendo simultaneamente. Cada paradigma desenvolve seu próprio conceito de cultura, que portanto é inseparável das outras proposições teóricas que o constituem.

O primeiro é o paradigma racionalista, correspondendo à escola francesa de Sociologia, tendo se desenvolvido a partir da crítica às categorias kantianas realizada por Durkheim. Trata-se de um pensamento essencialmente racionalista para o qual a idéia de cultura, 
profundamente apegada àquela de sociedade em oposição à ação individual, tem nas representações coletivas sua base. Mauss e, posteriormente, Lévi-Strauss se enquadram nesta escola. Cultura aqui é tomada como um sistema auto-contido de crenças e valores, como uma totalidade social supra-individual que explica o rito, a magia, os fatos, enfim, todas as práticas sociais, e que é constituída pelo conjunto inconsciente das relações que uma sociedade cria a partir dos recortes epistemológicos que estabelece por meio das categorias do entendimento, a "ossatura da inteligência", como diz Durkheim.

O segundo paradigma é o da escola britânica, chamada estrutural-funcionalista, profundamente empirista, onde Malinowski desenvolve a metodologia da imersão do antropólogo na cultura nativa como ferramenta crucial. A cultura aparece aqui como uma totalidade orgânica auto-regulada, seus vários domínios sendo tomados por sua dimensão funcional.

0 terceiro conceito de cultura se refere ao paradigma da escola histórico-culturalista norteamericana, que tem como epígono Boas. Profundamente empiricista, a escola culturalista introduz na antropologia uma forma de pensar a história e o indivíduo. Cultura é algo, de início, eminentemente geográfico, pois esta escola trabalha intensamente a idéia de área cultural. Localizada espacialmenmte, a cultura aparece como um conjunto de traços e padrões de 
comportamento, que à todo tempo está assimilando novos elementos e fazendo-se assimilar. Um dos autores mais citados quando o assunto é música e cultura , Alan Merriam, coloca-se fortemente neste modelo.

A quarta e última escola é aquela da antropologia interpretativa, o paradigma hermenêutico, que se desenvolve a partir das idéias de Geertz na segunda metade deste século. A cultura aparece aqui como texto a ser lido e traduzido pelo antropólogo através do trabalho de campo. A posição histórica e intelectual do autor é construtora do conhecimento, que é portanto produto intersubjetivo, e que se dá a partir de uma fusão de horizontes, a intersecção de dois universos sócio-culturais a partir das negocições de realidade entre pesquisador e pesquisado. A cultura foi descrita por Geertz, a partir de Weber, como uma teia de significados na qual o homem encontra-se enredado.

Com esta breve exposição pode-se esclarecer quatro conceitos de cultura absolutamente diferentes e mesmo incompatíveis entre si: cultura como inconsciente coletivo social, cultura como organismo auto-regulável, cultura como códigos de comportamento estáveis no espaço e na história, cultura como complexo de símbolos; ainda há outras possibilidades, como o caso da cultura do ponto de vista evolucionista ou neoevolucionaista, para o qual a cultura é um programa organizativo de direção única, ou o 
caso do paradigma da antropologia simbólica e da performance, no qual a cultura é fundada na ação e na experiência, constituindo-se símbolos compartilhados. Cada uma destas conceptualizações carrega em si, portanto, paradigmas teóricos profundamente distintos e deveria acarretar abordagens práticas igualmente diversas. O mesmo se pode dizer de outros conceitos, como aculturação ou observação participante. Enfim, há diferentes posicionamentos que constróem as concepções de homem, sociedade, cultura e história, assim como, em um estudo etnográfico, no processo de seleção, observação e interpretação de fatos há uma que teoria, explícita ou implícita, que determina o próprio dado e a orientação ou o rumo a ser seguido. Diversos problemas surgem quando se procura aplicar a noção de cultura sem referência à sua matriz antropológica, muitas vezes sem consciência mesmo quanto ao paradigma teórico como um todo. E creio que isto está ocorrendo frequentemente no panorama contemporâneo, onde os discursos e narrativas sobre cultura e identidade cultural estão sendo quase que banalizados. 


\section{"Educação musical"}

O impacto desta "culturalização" do mundo contemporâneo é igualmente forte no campo da educação. As abordagens psicológicas/cognitivistas de sabor universalista tiveram que abrir caminho para o relativismo cultural e a realidade regional. 0 debate entre educadores $\mathrm{e}$ antropólogos não é algo novo, mas tem sido muito intenso nas últimas décadas. Ao mesmo tempo que a antropologia tem fertilizado esta área no desenvolvimento de métodos mais qualitativos e etnográficos, há uma renovação dos estudos sobre enculturação, educação e crítica no campo da própria antropologia. Um exemplo muito atual disto é que na XXII Reunião Brasileira de Antropologia, a ser realizada em Brasília em julho deste ano, haverá um fórum sobre Antropologia e Educação, como aliás vem ocorrendo em encontros deste tipo já há alguns anos. Igualmente, no encontro nacional da $A B E M$, a ser realizada em Belém em setembro deste ano, pelo que me consta, a temática será "Currículos de Música e Cultura Brasileira". De fato, a influência da antropologia no campo da educação musical no Brasil já se faz sentir fortemente, por exemplo nos estudos etnográficos de Margareth Arroyo (1999), Luciana Prass (1998) e Marília Stein (1998), estudos que foram gerados na UFRGS sob a orientação de Elisabeth Lucas (1992, 1995a, 1995b), que tem sido uma importante coordenadora neste sentido. 
Mas ao mesmo tempo em que se tem valorizado idéias como "cultura", "valores regionais", "diversidade cultural", isto tudo no quadro geral da globalização e das sociedades pós-industriais, o pensamento social abrindo espaço para um relativismo cultural que questiona as generalizações universalizantes, não se pode dizer que as políticas culturais e educacionais estejam seguindo estas valorizações para além de seu discurso, que muitas vezes contradiz as práticas, ainda calcadas em modelos universalizantes e hegemônicos. Refiro-me particularmente a um caso que pretendo comentar aqui: aquele da realidade musical-sócio-cultural do Brasil atual e os currículos no ensino superior de música. Me parece que neste campo ocorre uma situação problemática com profundas raízes e implicações que pretendo apenas mencionar.

No Brasil o discurso multiculturalista está se tornando cada vez mais freqüente: está sendo construída uma imagem multicultural pósgilbertofreireana como uniforme para o país no cenário do concerto das nações globais. País multiracial, multicultural, onde a diferença faz a diferença. Este Brasil multiculturalizado tem uma colocação razoavelmente confortável no topo do mundo em pelo menos duas áreas: esporte, mais especificamente futebol, e música. Nas narrativas sobre a música brasileira que a idéia de mistura criativa de raças encontra talvez sua mais forte ressonância, narrativa esta realimentada em parte pela própria mídia nacional e em parte pela política 
cultural. De fato, a música popular brasileira tem sido, já há algumas dezenas de anos, uma das três músicas populares nacionais mais apreciadas e ouvidas em todo o planeta. 0 cenário da música popular contemporânea no Brasil é bastante fértil. A críticas de que há uma decadência são profundamente compromissadas com um modelo musicológico reacionário e teoricamente ultrapassado: aquele da superioridade técnica dos gêneros musicais formal e harmonicamente mais complexos. Destaco aqui algumas características do cenário atual que justificam este enfoque nãoapocalíptico: o enorme avanço do gosto do público jovem pela música brasileira, diferentemente dos anos 70 e 80; o desenvolvimento marcante e a valorização de acentos regionais; a retomada e a evalorização de práticas que estavam caindo em desuso, como a música de rabeca e várias festas populares; a reinvenção constante de novas variações de gêneros dançantes; enfim, estudos antropológicos e etnomusicológicos têm chamado a atenção para a riqueza do momento Cabe perguntar aqui por quê a música popular, um fenômeno de proporções tão impressionantes no mundo atual, é tão pouco estudada nas academias e universidades? Por que os currículos no ensino superior de música no Brasil são, em sua maioria, voltados para os compartimentos típicos da música erudita européia? Este direcionamento está dado não somente no conteúdo, mas no própria seleção e nomeação das disciplinas. Alguns exemplos: 
"História da Música" na verdade é muitas vezes "História da Música Erudita Européia", excluindo todo o resto da produção musical no mundo como se nem música fosse, ou ainda pior, delegando à música popular uma abordagem quantitativamente irrisória; "Análise Musical" aborda somente música erudita, apesar de já existirem várias metodologias de análise de música popular. Há inúmeros outros exemplos que apontam para a ausência absoluta ou uma presença extremamente modesta do repertório popular nos currículos superiores de música. Como se sustenta este direcionamento diante do cenário atual, que aponta para outro lado, aquele da cultura, da valorização do multiculturalismo, da força da musicalidade do povo brasileiro que é largamente respeitada em termos globais? Ao mesmo tempo, a virada pósmoderna instaura uma forte crise mundial das vanguardas e das elites intelectuais, e a música erudita brasileira está imersa em um profundo marasmo criativo e profissional. Ao que parece, a insistência curricular em desprezar a música popular instaura como que um vácuo cultural entre realidade e academia que simbolicamente acaba por prejudicar a criação do gosto e da excelência na própria música erudita.

Estes dois rótulos, popular e erudito, já tão gastos e desconstruídos pelo pensamento crítico desde o início da industrialização da cultura, parecem persistir no modelo de ensino de música não só no Brasil como também em outros países, como mostra Shepherd para o caso do rock na Inglaterra (1995). É uma 
dicotomia de fundo ideológico, refletindo o pensamento elitista de uma burguesia poderosa. A questão crucial é: interessa ou não que o Brasil desenvolva amplamente seu potencial musical? Como todos os discursos culturalistas atuais se referem, para isso que a resposta seja "sim" seria necessário mergulhar na especificidade cultural. Isto implica que se estabeleça uma profundo remodelamento das diretrizes do ensino de música no Brasil, que se repense com clareza a hegemonia do modelo euro-americano no ensino de música, que se avalie a ênfase na música erudita européia e a ausência da música popular no cerne mesmo dos currículos, e que se tenha coragem de derrubar estes muros, que são feitos de pura ideologia, e ouvir a música que está batendo à porta da academia, na expressão de Elisabeth Lucas (1992). Enfim, uma reformulação geral que a mim não parece estar à vista, e que toca em questões sensíveis e ambíguas, e dilemas difíceis: a solução seria mesmo cursos separados, como na UNICAMP e em outros lugares do mundo? Ou isto acaba sendo uma armadilha que reifica ainda mais os blocos?

Toda esta questão não é nova. A Sociologia da Educação, que se leva em conta o pensamento sobre o mundo pós-moderno, o interesse no cotidiano e na relativização do conhecimento, na realidade local, e que tem um interessante laço com a Educação musical brasileira em Jusamara Souza (1996), é uma abordagem promissora nesta discussão. Mas é parte da episteme pós-moderna o fato de que 
nenhuma questão é inteiramente nova, que há vários "nós" que ficaram para ser desatados. A antropologia da música e a etnomusicologia são ferramentas fundamentais neste processo. Para concluir, lembro que, no bojo das crises contemporâneas, o quadro da antropologia também se encontra hoje sem a autoridade de um paradigma claro; como vimos, na visão de Roberto Cardoso de Oliveira há uma influência simultânea daqueles quatro modelos. Os esforços unificadores são tão isolados entre si que acabam denotando uma maior fragmentação teórica, que afinal, é uma das características de nossa época. Mas é fundamental que se parta das conquistas dos anos sessenta para a frente, quando a ênfase deixou de ser a tradução e explicação da "cultura mental" e se dirigiu para a captação do ponto de vista do nativo, a sua visão do mundo. Enfim, emergiu ali uma antropologia interpretativa que vem trazendo diversas contribuições para o capital conceitual das humanidades, como as idéias de negociação de sentido, de encontro ou fusão de horizontes, da importância do diálogo e da voz dos nativos, de diferentes visões de mundo. Para Marcus e Fischer, a antropologia interpretativa opera simultaneamente em dois níveis: "fornece dados sobre outros mundos de dentro, e reflete sobre os fundamentos epistemológicos de tais dados". A retórica destes dados etnográficos, a etnografia, veículo chefe da antropologia, passa então por reformulações marcantes com Geertz (1989), que mostra o papel ativo da autoria do 
antropólogo nos dados etnográficos, mostrando como ele se manifesta no texto e o que ele autoriza com seu discurso; a autoridade (no sentido de competência autorizada) presente na discursividade do texto etnográfico é assim determinante e orientadora. É crucial admitir que o mesmo ocorre com os currículos de música se nos metemos a lê-los eles próprios como produção cultural: seus autores e executores elaboram um projeto que reflete eles mesmos. Neste sentido, a reformulação que mencionei à pouco é, também, uma espécie de auto-destruição. Mas ainda creio que ela é necessária, e que somente assim poderemos desenvolver aqui um sistema de excelência, tanto em música popular, erudita, experimental, etc.

No mundo neoliberal, muitos cientistas políticos têm notado estratégias do primeiro mundo que procuram evitar que se desenvolvam, nos países ditos emergentes, centros universitários de excelência científica. Em uma metáfora empregada recentemente por Heinz Dietrich (Dietrich e Chomsky,1999)2, estaríamos destinados a ser "bonsais em uma floresta de árvores gigantes". Mas isto pode se reverter, se houver coragem de não se desbastar a árvore (ou se deixar desbastá-la), deixando-a crescer sem limites. 


\section{Referências bibliográficas}

ARROYO, Margarete (1999) Representações Sociais sobre Práticas de Ensino e Aprendizagem Musical: um estudo etnográfico entre congadeiros, professores e estudantes de Música. Porto Alegre: Curso de Pós-Graduação em Música - UFRGS. (Tese de doutorado)

BAUMANN, Zygmunt (1992) A Sociological Theory of Postmodernity, In: P. Beilharz et alli (eds.) Between Totalitarianism and Postmodernity (A Thesis Eleven Reader), Cambridge: Cambridge University Press, pp 147-162.

CARDOSO DE OLIVEIRA, Roberto, (1988) Sobre Pensamento Antropológico, Rio de Janeiro: Tempo Brasileiro.

CLIFFORD, James (1988) The Predicament of Culture, Cambridge: Harvard University Press.

DIETRICH, Heinz e CHOMSKY, Noam (1999) A Sociedade Global: Educação, Mercado e Democracia, Blumenau: Editora da FURB. GEERTZ, Clifford (1989) El antropólogo como autor, Barcelona: Paidos.

KUHN, Thomas S. (1975) A Estrutura das Revoluções Científicas. São Paulo: Perspectiva. LUCAS, Maria Elizabeth (1995a) Etnomusicologia e Globalização da Cultura: Notas para uma Epistemologia da Música no Plural, Em Pauta, 9/10, dez/94 - abr/95, UFRGS, pp. 16-21. ,(1995b) Etnomusicologia e Educação Musical: 
perspectivas de colaboração na pesquisa.

Boletim do NEA - Núcleo de estudos avançados -

Educação Musical, v.3, n.1, p.9-15, abril, UFRGS, pp. 9-15., (1992) Música Popular, à porta ou aporta na academia? Em Pauta, 6, dez/1992, UFRGS, pp. 5-12.

LYOTARD, J-F. (1986) O Pós-Moderno, Rio de Janeiro: José Olympio.

MARCUS, G. E. e FISCHER, Michael (1986) Anthropology as Cultural Critique: An Experimental Moment in the Human Sciences, Chicago: The University of Chicago Press.

PRASS, Luciana. (1998) Saberes musicais em uma bateria de escola de samba: uma etnografia entre os "Bambas da Orgia". Porto Alegre: Curso de Pós-Graduação em Música - UFRGS. (Dissertação de Mestrado).

RUNDELL, John (1992) Introduction: The Symptom of Postmodernity, In: P. Beilharz et alli (eds.) Between Totalitarianism and Postmodernity (A Thesis Eleven Reader), Cambridge: Cambridge University Press, pp. 139-148.

SHEPHERD, John (1995) The Struggle for Culture: a sociological case study of the development of a national music curriculum, Boletim do NEA - Núcleo de estudos avançados Educação Musical, ano III, n.2, agosto/1995, UFRGS, pp.9-15. 
STEIN, Marília R. (1998) Oficina de música: uma etnografia dos processos de ensino e aprendizagem musical em bairros populares de Porto Alegre. Porto Alegre: Curso de PósGraduação em Música - UFRGS. (Dissertação de Mestrado).

VALENTE Ana Lúcia E. F, e GUSMÃO, Neusa Maria Mendes de (2000) Apresentação do Forum: Antropologia e Educação, XXII ${ }^{a}$ Reunião Brasileira de Antropologia.

Ver http://www.unicamp.br/aba/xxiirba/calen dario/F05\%20-\%

20Antropologia\%20e\%20Educa\%E7\%E3o.htm 